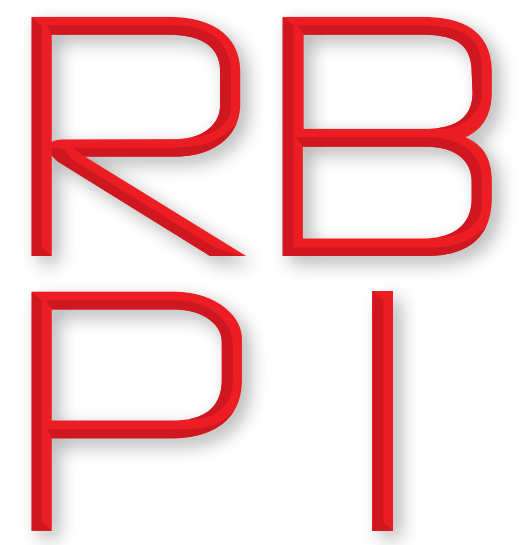

Revista Brasileira de Política Internacional ISSN 1983-3121

http://www.scielo.br/rbpi

\section{The limitations of IR theory regarding the environment: lessons from the Anthropocene (Erratum)}

DOI: http://dx.doi.org/10.1590/0034-73292017001019err

Rev. Bras. Polít. Int., 60(1): e018err, 2017

\section{The limitations of IR theory regarding the environment: lessons from the Anthropocene. Rev. Bras. Polít. Int., 60(1): e018, 2017}

http://dx.doi.org/10.1590/0034-73292017001019

On p. 1, in the title, which reads "ir", reads "IR"

On p. 1, in the title, which reads "anthropocene", reads "Anthropocene".

On p. 16, insert the text below before the paragraph initiated by "zFinnaly". The letter " $z$ " before Finally must be deleted.

Third, IR scholars will certainly understand that the "international" is composed of much more than the interactions among states or human beings. Exclusively state-centric and anthropocentric analyses will become increasingly obsolete in the Anthropocene because they will lack a whole range of actors, i.e., natural and material actors, which play a significant role in the complex web of global interactions. However, the "state-centric blindness" of IR still persists, making it difficult to notice other types of actors and developments in the international system. The articles published in the prestigious journal Global Environmental Politics corroborate this fact. As Dauvergne and Clapp (2016, p.3) note, those who publish in that journal "focus on formal statebased environmental governance (...) [dealing with] regimes or international agreements as a primary thematic focus, with topics ranging from how to measure the effectiveness of regimes to why 
states chose to ratify or oppose specific treaties." This is problematic because, since humans and nature are inseparable, humans, non-humans and biophysical elements interact with each other. This means that events are not only the result of human agency and humans cannot fully control the world (Connolly 2011). Furthermore, as Mitchell $(2014,5)$ highlights, "harm does not happen to humans in isolation, but rather to worlds composed of diverse beings." In IR, humans and their well-being are the ultimate subjects of security. Therefore, non-humans are instrumentalized to the point that even the superfluous needs of human beings are placed above the survival of non-humans. Hence, post-anthropocentrism is essential. Since humans and nature are one, a new ethical approach is needed, one that values non-humans not only because they are valuable to humans, but also because their existence should be respected and preserved. Only by recognizing the intrinsic value of living beings, and through a fair share of the planet between humans and non-humans, humanity will be able to create a "safe operating space" for itself. 